\title{
The Role of DJ-1 in the Pathogenesis of Endometriosis
}

\author{
Priyanka Rai, Sisinthy Shivaji*
}

Centre for Cellular and Molecular Biology, Hyderabad, India

\begin{abstract}
Background: Endometriosis is an estrogen-dependent disease causing pelvic pain and infertility in $10 \%$ of reproductiveaged women. Despite a long history of the disease the pathogenesis of endometriosis is poorly understood. It is known that the expression of several proteins is either up or down regulated during endometriosis, but their precise role remains to be determined. DJ-1 is one such protein that is upregulated in eutopic endometrium of women having endometriosis suggesting that DJ-1 may be involved in the pathogenesis of endometriosis.

Methodology and Principal Findings: The role of DJ-1 in the pathogenesis of endometriosis was investigated. For this purpose the influence of DJ-1 on endometrial cell survival, attachment, proliferation, migration, and invasion either by overexpressing DJ1 in normal endometrial cells or by knocking down DJ-1 expression in endometriotic cells using siRNA was investigated. The results indicated that DJ-1 protects endometrial cells from oxidative stress mediated apoptosis. Overexpression of DJ-1 in normal endometrial epithelial cells increases the adhesion on collagen type IV. However, no significant difference was observed incase of stromal cells. It was further demonstrated that DJ-1 regulates cell proliferation, migration, and invasion in normal endometrial and endometriotic epithelial cells whereas in the case of normal endometrial and endometriotic stromal cells, it regulates cell proliferation and invasion but not migration. Furthermore, the present study also indicated that DJ-1 regulates these cellular processes by modulating PI3K/Akt pathway by interacting and negatively regulating PTEN.
\end{abstract}

Conclusions: Abnormally high levels of DJ-1 expression may be involved in endometriosis, possibly by stimulating endometrial cell survival, proliferation, migration, and invasion.

Citation: Rai P, Shivaji S (2011) The Role of DJ-1 in the Pathogenesis of Endometriosis. PLoS ONE 6(3): e18074. doi:10.1371/journal.pone.0018074

Editor: Jean-Marc Vanacker, Institut de Génomique Fonctionnelle de Lyon, France

Received August 24, 2010; Accepted February 24, 2011; Published March 21, 2011

Copyright: (C) 2011 Rai and Shivaji. This is an open-access article distributed under the terms of the Creative Commons Attribution License, which permits unrestricted use, distribution, and reproduction in any medium, provided the original author and source are credited.

Funding: These authors have no support or funding to report.

Competing Interests: The authors have declared that no competing interests exist.

*E-mail: shivas@ccmb.res.in

\section{Introduction}

Endometriosis is a complex gynecological disease which occurs in $10 \%$ of reproductive age women. The disease is characterized by the presence and growth of endometrial tissue outside the uterus, causing pelvic pain, and infertility [1]. The pathogenesis of endometriosis is not clearly defined. However, the disease is thought to be principally caused by the shedding of viable endometrial cells into the peritoneal cavity by retrograde menstruation, followed by their implantation and growth on the surface of pelvic organs [1]. The formation of a lesion depends on the survival, attachment, growth, neoangiogenesis, and invasion of the endometrial cells at the ectopic sites [2]. This may be due to abnormalities of the eutopic endometrium itself, predisposing the cells to survive and implant ectopically [3].

Several studies have shown aberrant expression of genes/ proteins in endometriosis that are involved in regulating cellular processes like adhesion, proliferation, angiogenesis, immune dysfunction, and others [4-9]. Recently, using proteomics approach, we have investigated the differential expression of proteins in eutopic endometrium from women with and without endometriosis [9]. In this study it was observed that DJ-1 protein is upregulated in eutopic endometrium of women having endometriosis compared with controls. These findings suggest that DJ-1 may be involved in the pathogenesis of endometriosis.

The human DJ-1 gene comprises of seven exons and maps to 1p36.2-36.3, where many chromosome aberrations in cancers have been reported [10]. DJ-1 is ubiquitously present in cells and has been suggested to be a novel mitogen-dependent oncogene involved in a Ras-related signal transduction pathway [11]. More recently, high DJ-1 levels have been reported in various tumors, suggesting that abnormally expressed DJ-1 may play a role in cancer initiation and/or progression under certain circumstances [12-16] and may be a potential anticancer target [12-15]. DJ-1 protein affects cell survival, proliferation, and growth of cells in part, by modulating cellular signaling cascades such as PTENPI3K/Akt [16] and altering p53 activity [17,18]. DJ-1 has shown to convey protection against stresses (including oxidative stress, and endoplasmic reticulum stress) and proteasome inhibition $[12,19,20]$. It has been suggested that DJ-1 plays a role in antioxidative stress by eliminating reactive oxygen species and in transcriptional regulation of its target genes [18,20].

The pathological significance of DJ-1 in endometriosis has not been elucidated. Therefore, we investigated the effect of DJ-1 on normal endometrial as well in endometriotic cell survival, proliferation, motility, and invasion.

\section{Results}

Expression of DJ-1 in normal and endometriotic cell lines

An analysis of endogenous DJ-1 expression in normal human endometrial epithelial (HES) and stromal (Sht 290) cell lines and endometriotic epithelial (12-Z) and stromal (22-B) cell lines was 
performed. It was observed that the expression of DJ-1 protein was relatively higher in endometriotic cell lines (12-Z and 22-B) compared to normal endometrial cell lines (HES and Sht 290) (Figure 1A and 1B). Ishikawa, which is an adenocarcinoma cell line, was used to show that the DJ-1 expression levels in endometriotic cells were similar to that in endometrial cancer cells (Figure 1A and 1B).

DJ-1 protects against oxidative stress induced apoptosis

To investigate whether DJ-1 protects against oxidative stress mediated cell death, HES cells were transiently transfected with
DJ-1-GFP or GFP alone. After $48 \mathrm{~h}$, cells were exposed to $200 \mu \mathrm{M}$ hydrogen peroxide $\left(\mathrm{H}_{2} \mathrm{O}_{2}\right)$ for $4 \mathrm{~h}$. The cells were then collected, and the cell lysates were subjected to immunoblot analysis. We used the cleavage of the $116 \mathrm{kDa}$ PARP to an $89 \mathrm{kDa}$ fragment as a measure of cells undergoing cell death. As shown in Figure $1 \mathrm{C}$ and 1D, the cleaved form of PARP (89 kDa) was detected in cells transfected with GFP (control) and exposed to oxidative stress, whereas it was not detected in cells expressing DJ1-GFP and exposed to oxidative stress (Figure 1C and 1D). Furthermore, pro-caspase-9 was also processed into the active
A

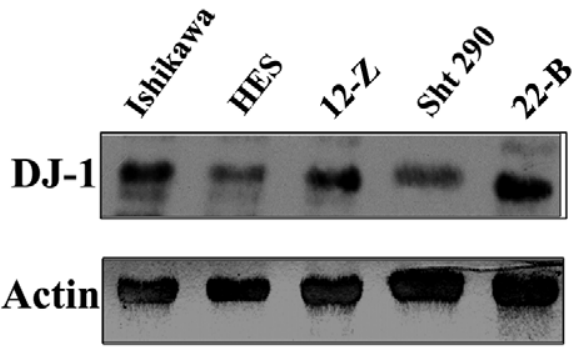

$\mathbf{C}$

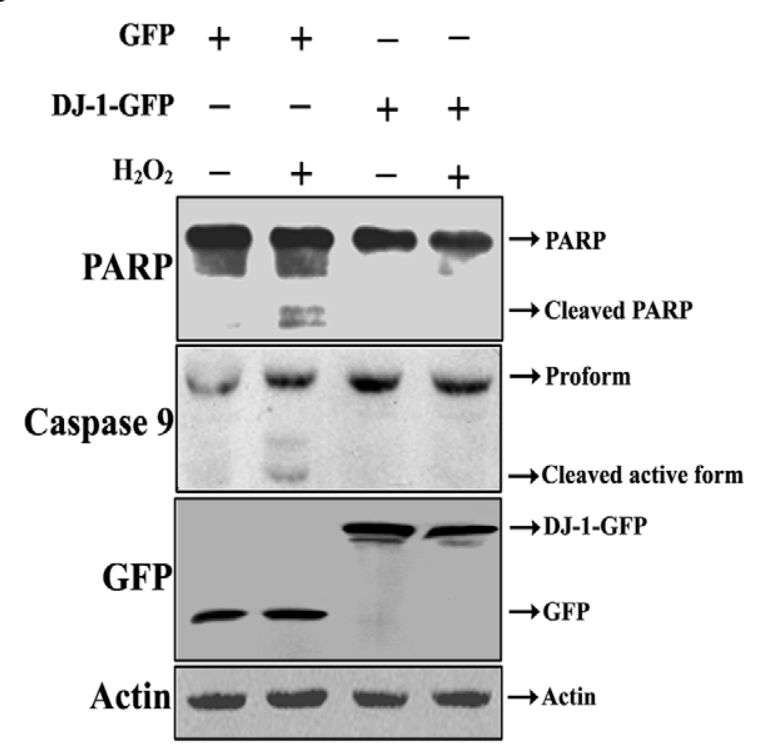

B

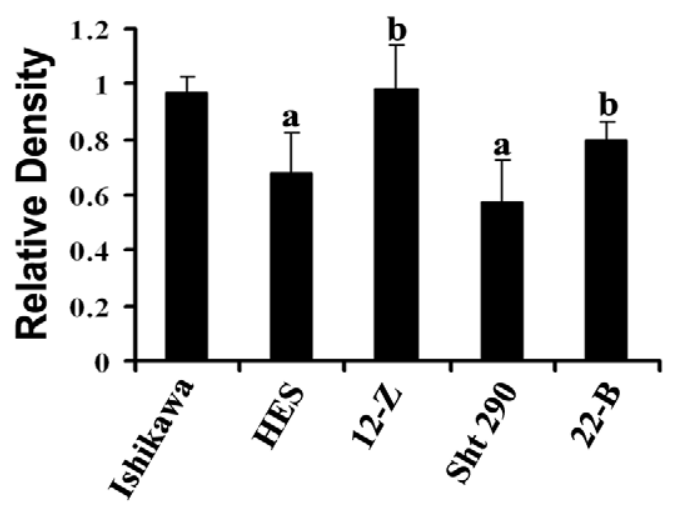

D

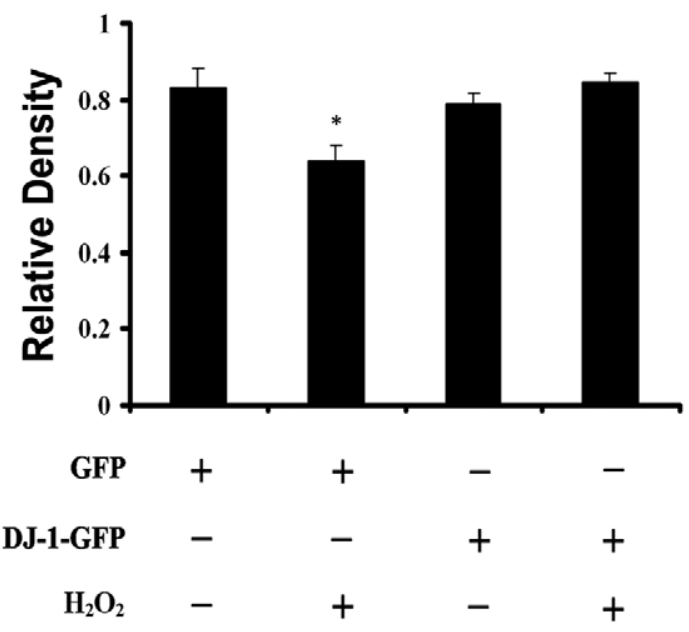

Figure 1. Expression of DJ-1. A, Expression of endogenous DJ-1 in Ishikawa, normal endometrial epithelial (HES) and stromal (Sht 290) cells and endometriotic epithelial (12-Z) and stromal (22-B) cells. B, Band density of DJ-1 relative to that of actin. Bars with different superscripts (a, b) indicate significant differences $(p<0.05)$ between normal endometrial and endometriotic cells, as determined by one way ANOVA with post hoc Bonferroni test. C, DJ-1 protects against apoptosis induced by oxidative stress as it inhibits the cleavage of PARP and caspase-9 induced by oxidative stress. Cells transfected with DJ-1-GFP or GFP were treated with or without $200 \mu \mathrm{M} \mathrm{H}_{2} \mathrm{O}_{2}$ for 4 h. Equivalent cell lysates were subjected to immunoblot analysis using antibodies against PARP, caspase-9, GFP, and actin. D, Densitometry analysis of PARP protein to actin ratio based on immunoblot analysis. *Asterisk indicates significant difference $(p<0.05$, as determined by Student's $t$-test) between cells transfected with DJ-1-GFP or GFP and treated with or without $200 \mu \mathrm{M} \mathrm{H}_{2} \mathrm{O}_{2}$ for $4 \mathrm{~h}$.

doi:10.1371/journal.pone.0018074.g001 
form (p35) in cells expressing GFP and exposed to oxidative stress but not in cells expressing DJ-1-GFP and exposed to oxidative stress (Figure 1C and 1D).

\section{Overexpression of DJ-1 leads to increased adhesion of normal endometrial epithelial cell}

Cellular adhesion of normal endometrial and endometriotic cells on various extracellular matrix components (ECM) was performed to understand whether endometriotic cells have the ability to attach at ectopic location. For this, normal endometrial and endometriotic cells were plated on dishes precoated with various ECM components. As shown in Figure 2A, endometriotic epithelial cells (12-Z) attached significantly more on fibronectin and laminin but not on collagen type IV when compared to normal endometrial epithelial cells (HES). Endometriotic stromal cells (22-B) show more attachment on laminin but less on collagen type IV when compared with normal endometrial stromal cells (Figure 2B). However, no significant difference in attachment was observed between normal endometrial and endometriotic stromal cells on fibronectin (Figure 2B).

To determine whether DJ-1 augments cellular adhesion, normal endometrial cells were infected with DJ-1 or control adenovirus for $24 \mathrm{~h}$ and cell adhesion assay was performed. It was observed that HES cells overexpressing DJ-1 show increased attachment on collagen type IV when compared with controls. The attachment was found to be decreased on fibronectin and laminin (Figure 2C). This finding is interesting, as collagen type IV is one of the major matrix components found in the basement membrane of normal tissue and organ [21]. We have checked the expressions levels of DJ-1 on various extracellular matrix components after infection with DJ-1 adenovirus using immunoblotting, the expression levels of DJ-1 was found to be similar (Figure S1). Similar experiments were carried out using Sht 290 cells. With this cell line, no significant difference in attachment to collagen type IV, fibronectin or laminin was observed between DJ-1 overexpressing cells and controls (Figure 2D).

\section{Effect of DJ-1 on endometriotic and endometrial cell proliferation}

The role of DJ-1 in endometrial and endometriotic cell proliferation was ascertained by using siRNA and overexpression approach. The success of siRNA transfection was $85-90 \%$ and DJ1 gene silencing was upto about $80 \%$ in endometriotic cells (Figure $\mathrm{S} 2 \mathrm{~A}$ and $\mathrm{S} 2 \mathrm{~B}$ ). The cell growth kinetics indicated that downregulation of DJ-1 by silencing DJ-1 gene decreases endometriotic epithelial and stromal cell proliferation by $\sim 2.5$ and $\sim 1.5$ fold, respectively when compared with controls (Figure $3 \mathrm{~A}$ and $3 \mathrm{~B}$ ). However, the inhibitory effect was more in endometriotic epithelial cells than in stromal cells. The experiment was also repeated using a second siRNA targeting $\mathrm{DJ}-1$, and similar results were obtained as shown in Figure S2C and S2D.

Further we determined, whether overexpression of DJ-1 affects cell proliferation in normal endometrial cells. Overexpression of DJ-1 in normal endometrial epithelial cells enhances cell proliferation by 1.4 fold within $48 \mathrm{~h}$ and it was 1.83 fold more by $72 \mathrm{~h}$ when compared with controls (Figure 3G). In endometrial stromal cells, the cell proliferation assay was performed up to $192 \mathrm{~h}$ as it is a slow growing cell line. Growth kinetics results showed that overexpression of DJ-1 increases the stromal cell proliferation by 1.5 fold at $96 \mathrm{~h}$ (Figure 3D). The expression levels of DJ-1 after infection with DJ-1-GFP adenovirus and control was checked by immunoblotting using GFP antibody (Figure S3A and $\mathrm{S} 3 \mathrm{~B})$. It was observed that the expression levels of DJ-1 increases in a time dependent manner.

\section{DJ-1 plays a role in endometrial cell migration and invasion in endometriosis}

Wound healing assay was performed to determine the migration capacity of normal endometrial cells and endometriotic cells. In endometriotic epithelial cells (12-Z), the wound was completely healed in $14 \mathrm{~h}$ whereas in human endometrial epithelial cells (HES), the wound took more than $24 \mathrm{~h}(\sim 36 \mathrm{~h})$ to heal, suggesting that endometriotic epithelial cells migrate faster than normal endometrial epithelial cells (Figure S4A). However, in case of endometriotic (22-B) and normal stromal cells (Sht 290) no significant difference in migration was observed (Figure S4B). To determine whether DJ-1 influences endometriotic and normal endometrial cell migration, and invasion, DJ-1 was knocked down in endometriotic epithelial and stromal cells and then the wound healing assay was performed. Interestingly, it was observed that in endometriotic epithelial cells (12-Z) transfected with ctrl siRNA, the wound healed completely in $14 \mathrm{~h}$ but cells in which DJ-1 gene was knocked down, wound healing took more than $14 \mathrm{~h}(\sim 24 \mathrm{~h})$ to heal (Figure 4A), suggesting that DJ-1 increases endometriotic epithelial cell migration. In case of endometriotic stromal cells transfected with siRNA no significant difference was observed in migration rate compared to the corresponding control (Figure $\mathrm{S} 5 \mathrm{~A})$. The effect of DJ-1 on migration was further confirmed by overexpressing DJ-1 in normal endometrial epithelial and stromal cells by using DJ-1 adenovirus. We observed that, in cells overexpressing DJ-1, wound was completely healed in $24 \mathrm{~h}$ as compared to control, in which wound was healed in $\sim 36 \mathrm{~h}$ (Figure 4B). However, overexpression of DJ-1 does not significantly affect migration in normal endometrial stromal cells (Figure S5B).

Since DJ-1 regulates the process of cell migration, we next determined whether $\mathrm{DJ}-1$ is involved in cell invasion. Results indicated that over-expression of DJ-1 increases the invasion of normal endometrial epithelial and stromal cells by approximately 32 and $35 \%$, respectively (Figure 5A and 5C). Regulation of invasion potential by $\mathrm{DJ}-1$ was further confirmed by knocking down DJ-1 expression using siRNA. Results indicated that silencing of DJ-1 gene decreased invasion of endometriotic epithelial and stromal cells by approximately 68 and $36 \%$, respectively (Figure 5B and 5D).

\section{Involvement of DJ-1 in PI3K-AKT Pathway}

Recent reports have demonstrated that DJ-1 modulates the PI3K-Akt survival pathway by negatively regulating the function of the tumor suppressor gene PTEN [16]. Therefore, attempts were made to analyze the function of $\mathrm{DJ}-1$ in the PI3K signaling pathway, focusing on the interaction of DJ-1 with PTEN. To investigate, the effect of DJ-1 overexpression on Akt phosphorylation and PTEN expression, HES cells were transiently transfected with DJ-1-GFP or GFP alone. After 48 h, cell lysates were prepared and subjected to immunoblot analysis. In HES cells, overexpression of DJ-1 increases the levels of phosphorylated Akt while the expression level of PTEN was decreased (Figure 6A and $6 \mathrm{~B})$. To further determine whether DJ-1 interacts with PTEN, HES and 12-Z cells were co-transfected with GFP-PTEN and myc-DJ-1 and after $48 \mathrm{~h}$ immunofluorescence was performed. DJ1 and PTEN were found to be expressed in cytoplasm and nucleus and confocal analysis showed that DJ-1 colocalizes with PTEN (Figure 6D). Immunofluorescence and confocal studies at endogenous level was also carried out in HES and 12-Z cells by staining for endogenous DJ-1 and PTEN. Consistent with overexpression studies, endogenous DJ-1 colocalizes with endogenous PTEN (Figure 6D). We have also performed immunofluorescence and confocal analysis in Ishikawa cells, which are PTEN negative. 

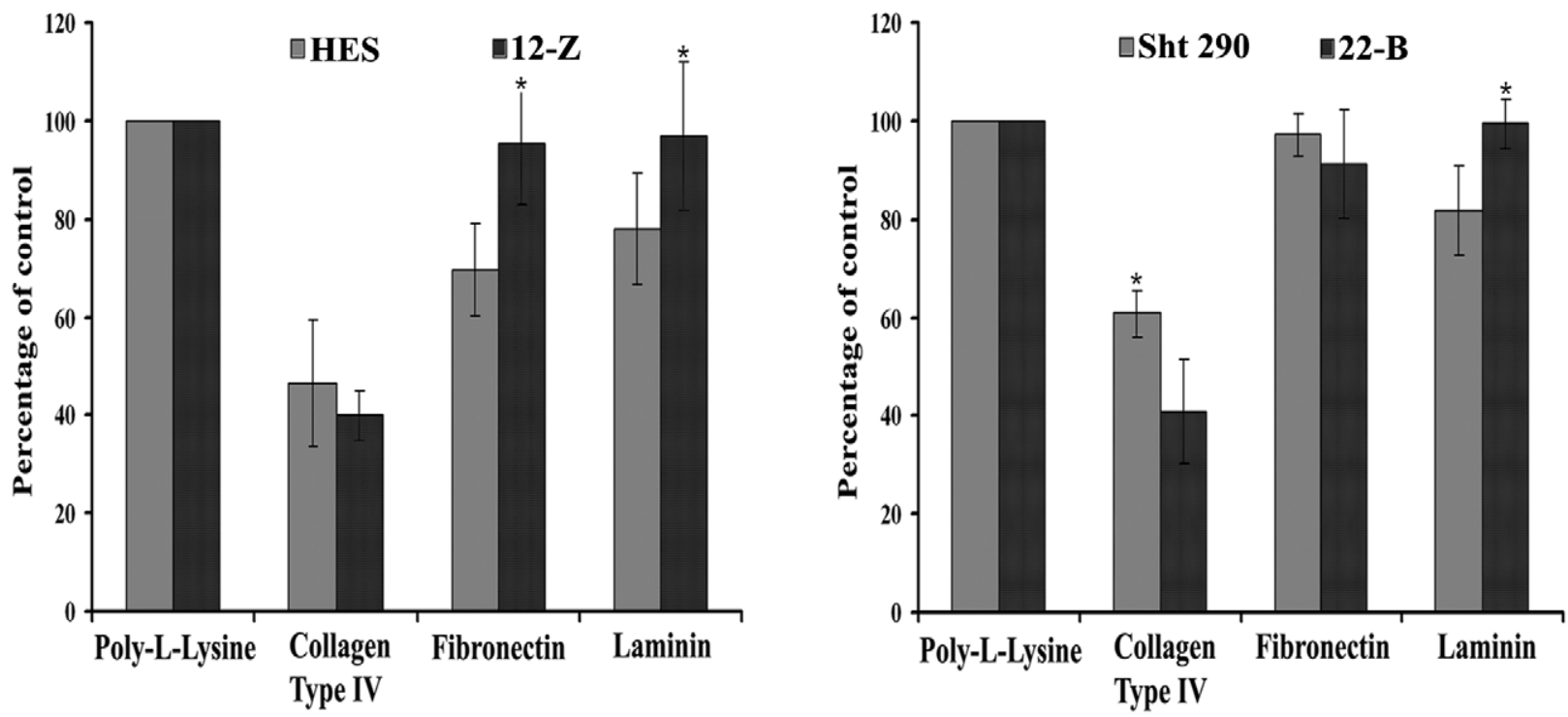

C
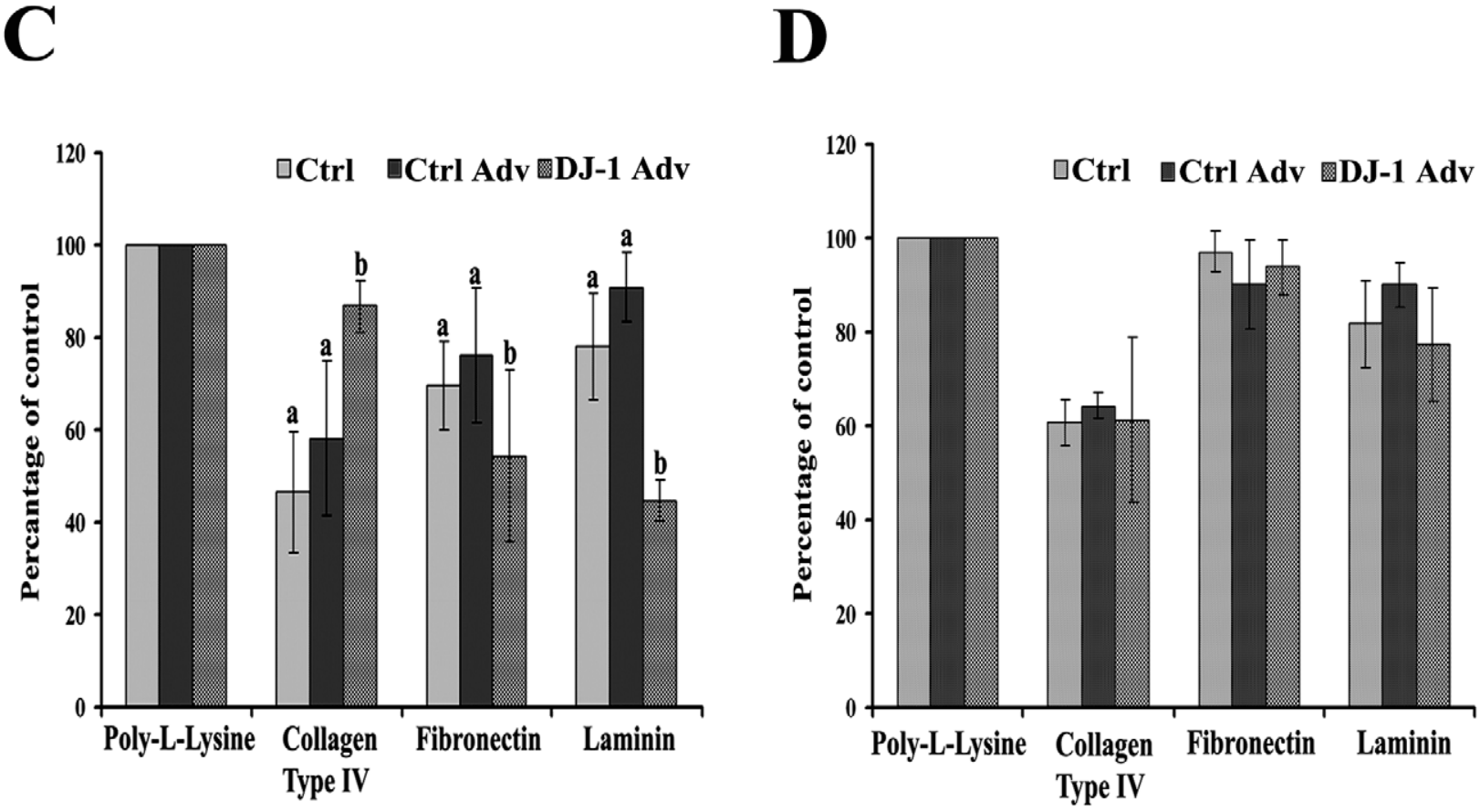

Figure 2. Role of DJ-1 in normal endometrial epithelial and stromal cell attachment. Attachment of normal endometrial epithelial (HES) and endometriotic epithelial (12-Z) cells (A) and normal endometrial stromal (Sht 290) and endometriotic stromal (22-B) cells (B) on various extracellular matrix (ECM) components. $C$ and D depict the effect of DJ-1 overexpression on normal endometrial epithelial (C) and stromal (D) cell attachment. Cells either alone (Ctrl) or infected with control adenovirus (Ctrl Adv) or with DJ-1 adenovirus (DJ-1 Adv) for $24 \mathrm{~h}$ were plated on a 96 well plate coated with various ECM components. After 20 min of attachment, MTT assay was performed for determining cell attachment. In figures A and B, * indicates significant difference between HES and 12-Z and Sht 290 and 22-B cells, respectively. In figure C, bars with different superscripts (a, b) indicate significant differences $(P<0.05)$ between cells overexpressing $D J-1$ and controls, as determined by one way ANOVA with post hoc Bonferroni test. Numerical data are expressed as mean \pm SE of three independent experiments. doi:10.1371/journal.pone.0018074.g002

The cells were co-transfected with GFP-PTEN and myc-DJ-1. DJ1 and PTEN were found to be expressed in cytoplasm and nucleus and confocal analysis showed that the extent of colocalization is more in the nucleus than in the cytoplasm (Figure S6). The immunofluorescence studies at endogenous level were also carried out in HeLa cells (human cervical epithelial cancerous cell line) by staining for endogenous DJ-1 and PTEN. Consistent with HES and $12-\mathrm{Z}$ studies, endogenous $\mathrm{DJ}-1$ colocalizes with endogenous 
A

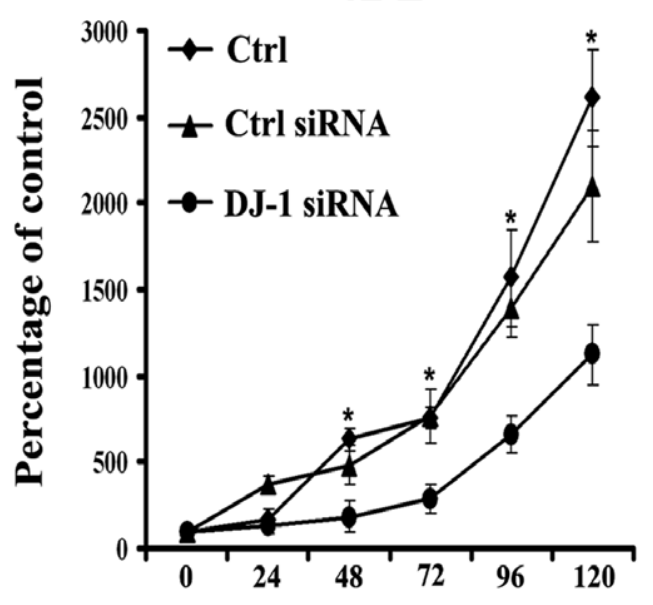

Hours after inhibition

C

\section{HES}

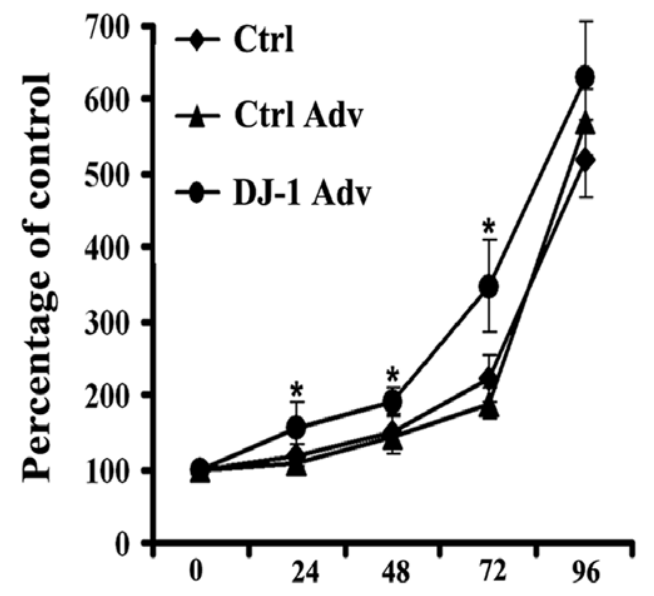

Hours after infection
B

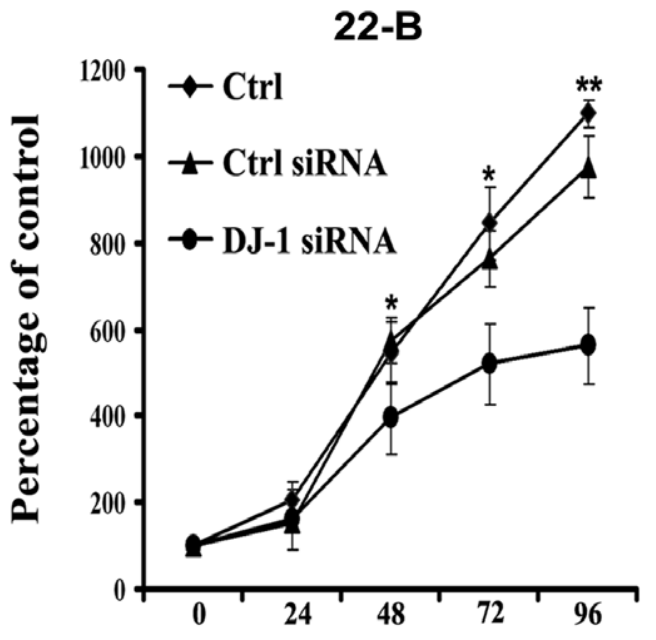

Hours after inhibition
D

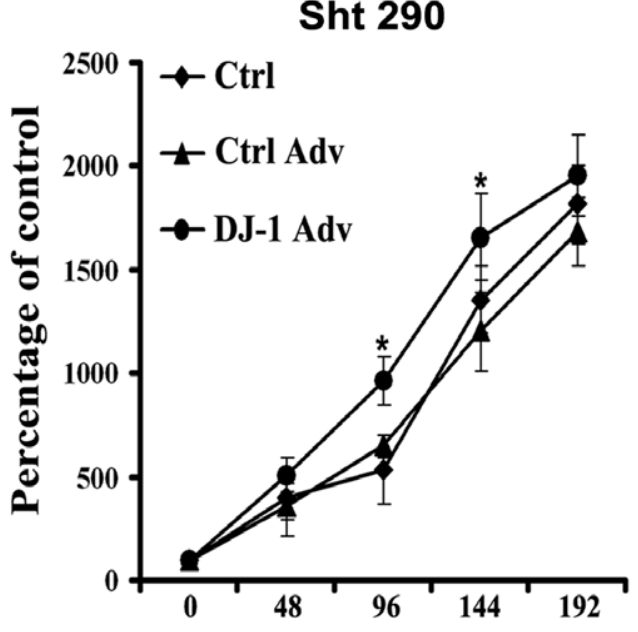

Hours after infection

Figure 3. Role of DJ-1 on cell proliferation. Endometriotic epithelial (12-Z) (A) and stromal (22-B) (C) cells were transfected with either DJ-1 siRNA or ctrl siRNA and normal endometrial epithelial (HES) (B) and stromal (Sht 290) (D) cells were infected with control adenovirus (Ctrl Adv) or with DJ-1-GFP adenovirus (DJ-1 Adv), plated on 96 well plate and cell proliferation was determined by MTT assay. Results are expressed as the percentage of control at time $0 \mathrm{~h}$. *Asterisk indicates significant differences $(P<0.05)$ between either DJ-1 knockdown cells or cells overexpressing DJ-1 and controls, as determined by one way ANOVA with post hoc Bonferroni test. Cells which were not transfected with either DJ-1 siRNA or which were not infected with the adenovirus served as controls. Numerical data are expressed as mean \pm SE of three independent experiments.

doi:10.1371/journal.pone.0018074.g003

PTEN (Figure S6). The interaction was further validated by coimmnoprecipitation assay. HES cells were co-transfected with GFP-PTEN and myc-tagged DJ-1 followed by immunoprecipitation with anti-myc antibody and then immunoblotted with antimyc and anti-GFP antibodies. The results demonstrated that GFPPTEN was present in anti-myc precipitated samples (Figure 6C), suggesting that DJ-1 interacts with PTEN. Our results show that DJ-1 interacted with PTEN and its overexpression resulted in decreased expression of PTEN which led to increased phosphorylation of Akt.

\section{Discussion}

In endometriosis, the eutopic endometrium of women shows aberrant expression of many genes/proteins that are involved in regulating various cellular processes [4-9]. Recently, we demonstrated that many proteins are differentially expressed in various stages of endometriosis [9]. DJ-1 is one of the proteins that is found to be consistently upregulated in various stages of endometriosis [9]. In the present study, the role for DJ-1 in endometrial cell survival, proliferation, migration, and invasion either by over- 


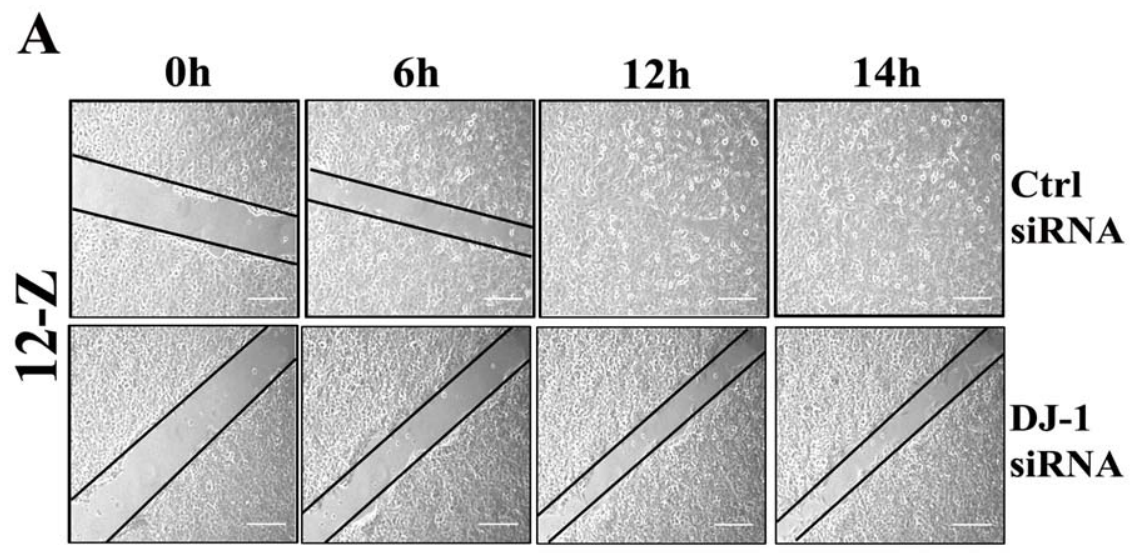

\section{B}

Ctrl Adv

DJ-1 Adv

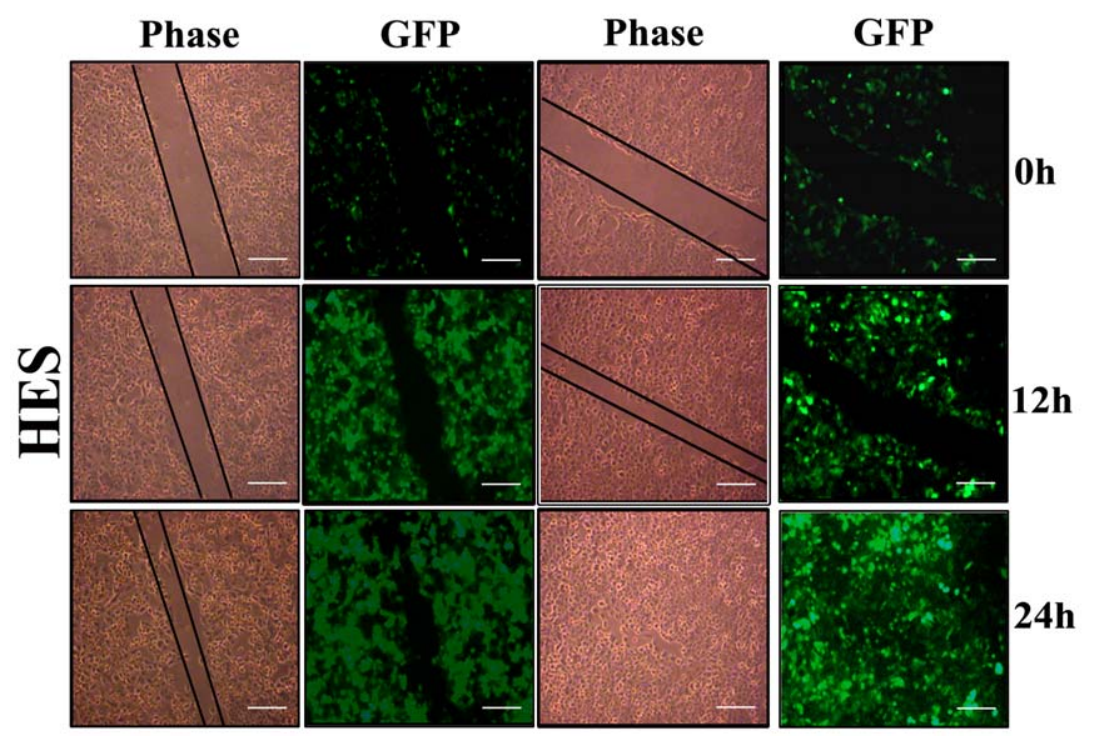

Figure 4. Role of DJ-1 in normal endometrial and endometriotic epithelial cell migration. Inhibition of DJ-1 in endometriotic epithelial cells (12-Z) results in decreased migration (A). Overexpression of DJ-1 in normal endometrial epithelial cells (HES) results in increased migration (B). Cells were either transfected with DJ-1 siRNA, or with control siRNA and $48 \mathrm{~h}$ post transfection wound assay was performed. For overexpression, cells were either infected with DJ-1-GFP adenovirus or control adenovirus and $24 \mathrm{~h}$ post infection wound assay was performed. Photographs were taken by time lapse microscopy at initial time $(0 \mathrm{~h})$ till the termination of the experiments. The experiments were repeated in triplicates. doi:10.1371/journal.pone.0018074.g004

expressing DJ-1 in normal endometrial cells or by knocking down DJ-1 expression in endometriotic cells using siRNA has been investigated. The results provide the first evidence that DJ-1 may be involved in the pathogenesis of endometriosis by regulating endometrial cell survival, proliferation, migration, and invasion at ectopic sites.

DJ-1 expression levels were found to be more in endometriotic epithelial and stromal cells than normal endometrial epithelial and stromal cells consistent with the finding of our proteomic analysis [9]. Increased expression of DJ-1 protein in endometriotic cell lines suggests its important role in the pathophysiology of endometriosis. DJ-1 has multiple roles in various biological processes such as cellular transformation [11], protection against oxidative stress mediated apoptosis $[18,19,20]$, and transcriptional regulation [18,22] and in cellular proliferation $[15,23]$. Our results demonstrated that overexpression of $\mathrm{DJ}-1$ protects normal endometrial cells against oxidative stress induced cell death, which is in agreement with earlier reports $[19,20]$.

Endometriosis is characterized by adherence, growth, proliferation, migration, and infiltration of endometrial tissue to the surrounding tissue [2]. It has been demonstrated, using in vitro model of the early endometriotic lesion, that endometrial cells attach to mesothelial cells and this process is dependent on the source of endometrial cells [24]. Therefore, firstly we compared the adhesion capacity of normal endometrial and endometriotic cells. It was observed that both the cell types have different adherence capabilities on various ECM components. Therefore, we next determined whether increased $\mathrm{DJ}-1$ protein expression in normal endometrial cells were associated with their increased capacity to attach on various ECM components. Results indicated that normal endometrial epithelial cells overexpressing DJ-1 show different attachment capacity on various ECM components. 
A

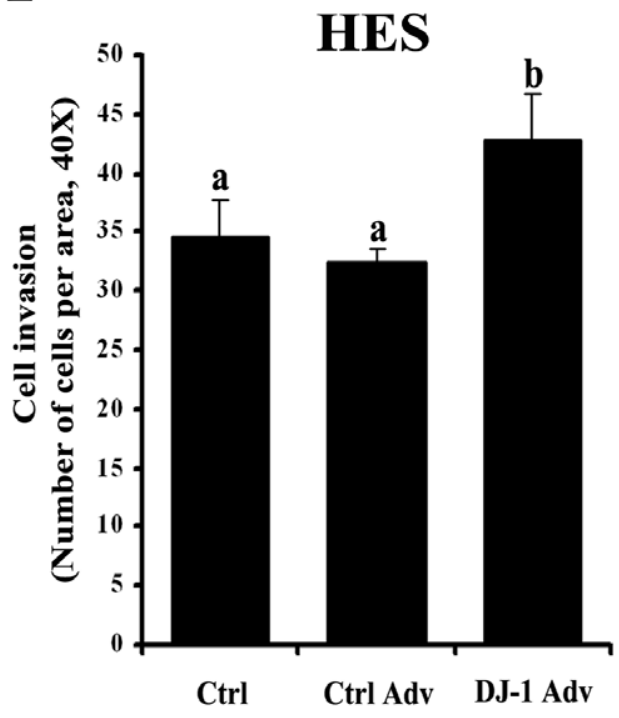

B

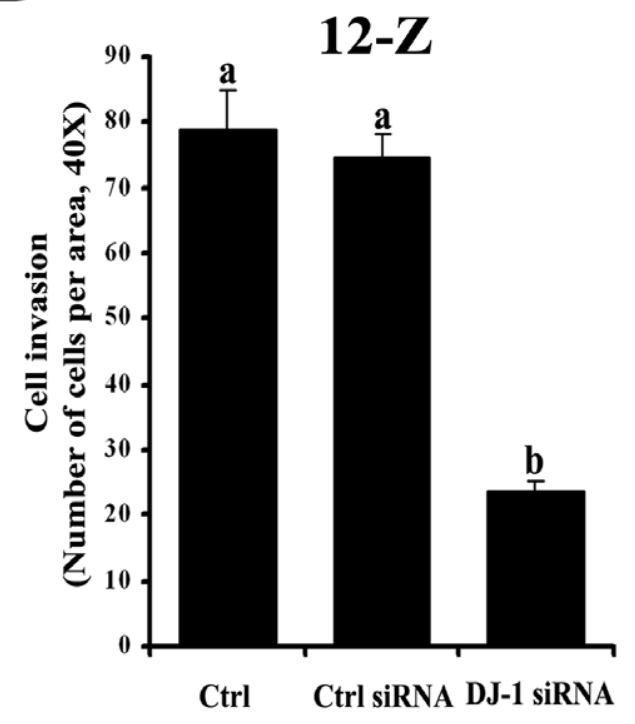

D

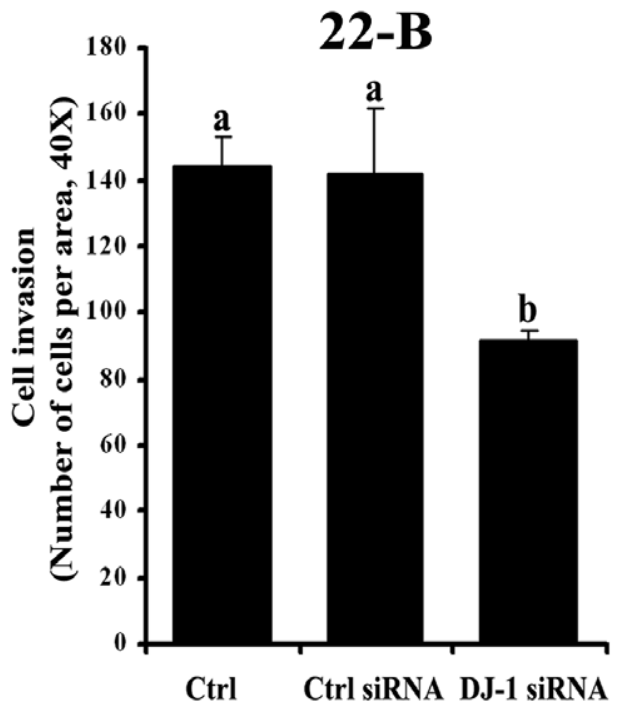

Figure 5. Role of DJ-1 in normal endometrial and endometriotic cell invasion. Normal endometrial epithelial, HES (A) and stromal, Sht 290 (C) cells were infected with control adenovirus (Ctrl Adv) or with DJ-1-GFP adenovirus (DJ-1 Adv) and endometriotic epithelial, 12-Z (B) and stromal, 22-B (D) cells were transfected with either DJ-1 siRNA or ctrl siRNA. At the end of incubation period, matrigel invasion assay was performed. Results are expressed as the number of cells per area at 40X. Bars with different superscripts $(a, b)$ indicate significant differences $(p<0.05)$ between either cells overexpressing DJ-1 or DJ-1 knockdown cells and controls, as determined by one way ANOVA with post hoc Bonferroni test. Cells which were not transfected with either DJ-1 siRNA or which were not infected with the adenovirus served as controls. Numerical data are expressed as mean $\pm \mathrm{SE}$ of three independent experiments. doi:10.1371/journal.pone.0018074.g005

Interestingly, cells overexpressing DJ-1 attach more on collagen type IV, which is the major ECM component of basement membrane of most tissues and organs in humans [21].

Recent reports have shown that inactivation of DJ-1 by RNAmediated interference (RNAi) resulted in inhibition of the proliferation in leukemia and laryngeal carcinoma cells [15,23]. Therefore, we next determined whether DJ-1 regulates normal endometrial and endometriotic cell proliferation. Our result demonstrated that over-expression of DJ-1 significantly increases rate of cell proliferation in normal endometrial epithelial cells as well as in stromal cells. Further, inhibition of DJ-1 expression by
siRNA resulted in decreased cell proliferation of endometriotic epithelial and stromal cells. Taken together, these results suggest that $\mathrm{DJ}-1$ is also involved in regulation of endometrial and endometriotic cell proliferation.

Endometriosis is characterized by migration and invasion of endometrial cells at ectopic sites [2]. This led us to investigate the migration ability of normal endometrial and endometriotic cells. We observed that the endometriotic epithelial cells migrate faster than normal endometrial epithelial cells. On the contrary, no differences in rates of migration between normal endometrial and endometriotic stromal cells were observed. This difference might 


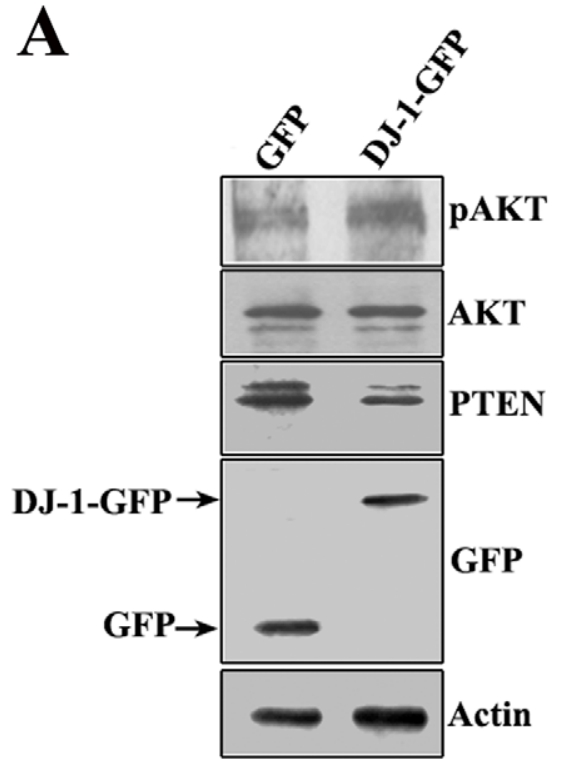

B

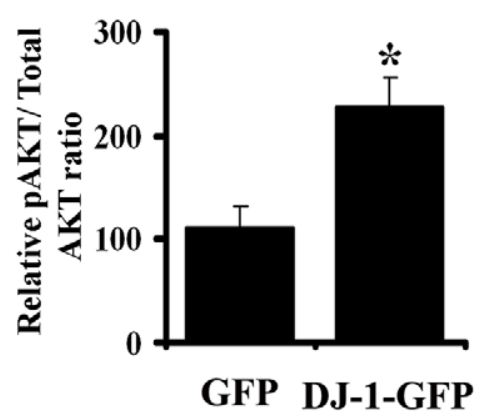

D
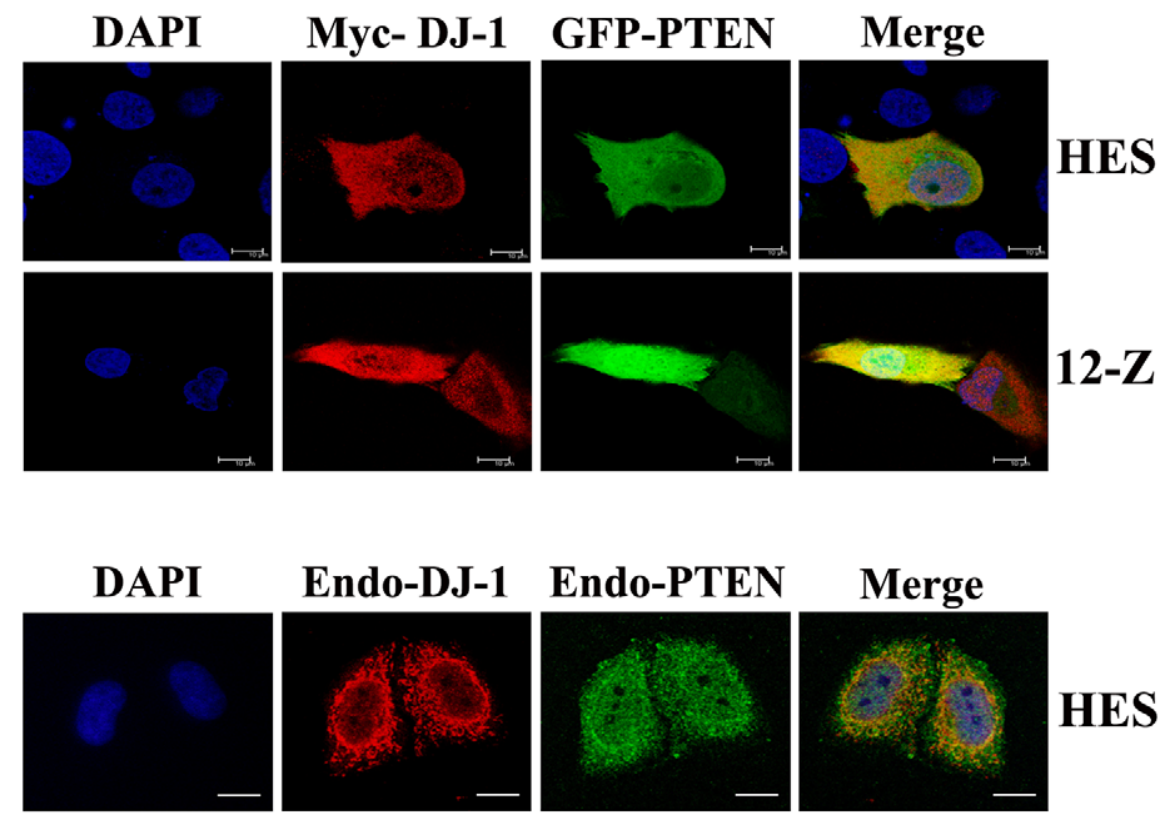

HES
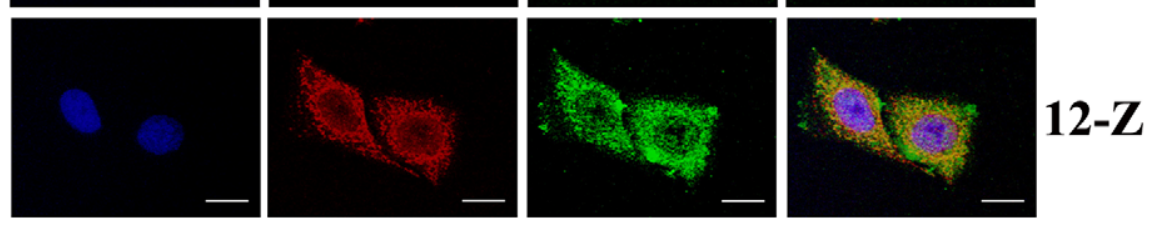

Figure 6. Involvement of DJ-1 in PI3K-AKT pathway. DJ-1 increases the phosphorylation of Akt and downregulates PTEN expression (A). HES cells were transfected with DJ-1-GFP or GFP. After $48 \mathrm{~h}$, transfected cells were collected for immunoblot analysis using anti-pAkt, anti-Akt, anti-PTEN and anti-GFP antibody. Actin was used as an internal control. Densitometry analysis of pAKT to total AKT ratio based on immunoblot analysis in HES cells transfected with DJ-1-GFP or GFP cells (B). *Asterisk indicates significant difference $(p<0.05$, as determined by Student's $t$-test) between cases and controls. DJ-1 interacts with PTEN (C). GFP-PTEN was co-immunoprecipitated with Myc-DJ-1. Lysates from HES cells co-transfected with myc-DJ-1 and GFP-PTEN were subjected to IP with anti-myc antibody. Immuoprecipitates and input lysates were analyzed by immunoblotting with anti- Myc and anti-GFP antibodies. Co-localization of DJ-1 with PTEN (D). HES and $12 Z$ cells transfected with GFP-PTEN and myc-DJ-1 were fixed and stained with anti-myc antibody (red). HES and $12 Z$ cells were stained with antibodies against PTEN (green) and DJ-1 (red). The images were visualized with a confocal microscopy.

doi:10.1371/journal.pone.0018074.g006 
be due to the inherent nature of these cell types. Since the migration rates of normal endometrial and endometriotic cells are different, we next determined whether DJ-1 is associated with endometrial and endometriotic cell migration as well as invasion potential. Results indicated that overexpression of DJ-1 significantly increases the migrating and invading potential of normal endometrial epithelial cells. Further, inhibition of DJ-1 by siRNA significantly decreased the rate of migration and invasion in endometriotic epithelial cells. Interestingly, we observed that neither over-expression of DJ-1 nor inhibition of DJ-1 affects the migration potential of normal endometrial stromal cells and endometriotic stromal cells, respectively. But, overexpression of DJ-1 leads to an increase in the invading potential of normal endometrial stromal cells. Inhibition of DJ-1 resulted in decrease in invasion potential. These observations suggest that DJ-1 regulates migration and invasion in endometrial and endometriotic epithelial cells but only regulates the process of invasion in stromal cell type. This difference might be due to the inherent nature of these two cell types. Such difference between the behavior of endometrial and endometriotic epithelial and stromal cells have been previously reported by Banu et al. [25]. However, the underlined molecular mechanisms for these selective effects are unknown.

In the process of deciphering the role of $\mathrm{DJ}-1$ in endometriosis, we demonstrated that $\mathrm{DJ}-1$ regulates endometrial and endometriotic cell survival, proliferation, migration, and invasion. Further, an attempt has been made to elucidate the molecular mechanisms underlying the DJ-1 dependent cell survival, proliferation, migration, and invasion. Since DJ-1 modulates the PI3K-Akt survival pathway by negatively regulating the function of the tumor suppressor gene PTEN [16], we assessed the expression levels of phosphorylated Akt and PTEN upon DJ-1 overexpression. The results showed that over-expression of DJ-1 increases the levels of phosphorylated Akt but decreases PTEN levels, which is consistent with previous reports $[15,16]$. We also demonstrated using colocalization and co-immunoprecipitation assays that DJ-1 interacts with PTEN. DJ-1 inhibits PTEN phosphatase activity through direct interaction of DJ-1 with PTEN in a manner dependent on the oxidative status of C106, resulting in activation of Akt, which promotes cellular transformation [26]. Very recently, Davidson et al. [27], have shown that both the lipid and protein phosphatase activities contribute significantly to the inhibition of both invasive morphology and proliferation. Our study implies that DJ-1 regulates endometrial cell survival, proliferation, migration, and invasion by modulating PI3K-Akt survival pathway by interacting and negatively regulating PTEN. However, the involvement of other mechanisms by which DJ-1 regulates theses cellular processes cannot be ruled out.

In conclusion, in this study we examined the possible role of DJ1 in the pathogenesis of endometriosis. The results from the present study suggest that DJ-1 protein is highly expressed in endometriotic cells. The increased expression of DJ-1 regulates survival, migration, and invasion of normal endometrial epithelial and stromal cells, and knocking down DJ-1 expression decreases growth, migration, and invasion of endometriotic epithelial and stromal cells, suggesting that DJ-1 might be playing an important role in the pathogenesis of endometriosis.

\section{Materials and Methods}

\section{Materials}

The reagents used in this study were: DMEM, phenol red free DMEM, FCS, and antibiotics (Invitrogen, Carlsbad, CA). PARP antibody (Roche, Mannheim, Germany), GFP antibody (Clontech,
Mountain View, CA), actin, phospho-Akt, Akt and PTEN antibodies (Santa Cruz, CA), Caspase-9 antibody (Millipore, Billerica, MA), DJ-1 antibody (MBL International, Woburn, MA), HRP conjugated secondary antibodies (Sigma-Aldrich, St. Louis, MO), Cy3 and Alexa fluor 488 conjugated secondary antibodies (Jackson Immuno Research, Baltimore, PA) and tissue culture dishes and plates (Corning Inc., Corning, NY). The other chemicals used were molecular biological grade from Sigma-Aldrich.

\section{Cell lines}

Immortalized human endometriotic epithelial cells (12-Z) and stromal cells (22-B) [28] and immortalized human endometrial surface epithelial cells (HES) [29] and stromal cells (Sht 290) [30] were used in the study. $12-Z$ and $22-B$ cells were a generous gift from Dr. A. Starzinski-Powitz, Institut für Zellbiologie und Neurowissenschaft, Johann Wolfgang Goethe-Universität, Frankfurt, Germany. HES cells were a generous gift from Dr. Asgerally T. Fazleabas, University of Illinois at Chicago, Illinois, USA. Sht 290 cells were a generous gift from David G. Kaufman, University of North Carolina at Chapel Hill, North Carolina, USA. 12-Z and 22-B cells were cultured in DMEM containing 10\% FCS and HES and Sht 290 cells were maintained in phenol red free DMEM containing $10 \%$ and $2 \%$ charcoal treated FCS, respectively. The media also contained penicillin $(100 \mathrm{U} / \mathrm{ml})$ and streptomycin $(100 \mathrm{~g} / \mathrm{ml})$. Cells were maintained in a humidified atmosphere of $5 \% \mathrm{CO}_{2}$ in air at $37^{\circ} \mathrm{C}$.

\section{Small interfering RNA}

Cells were transfected with $200 \mathrm{nM}$ DJ-1 SMARTpool siRNA that specifically targets the DJ-1 gene or non silencing control using Lipofectamine-2000 according to manufacturer's instructions. An individual DJ-1 siRNA is also used. SiRNA duplexes were obtained from Dharmacon, Inc. (Lafayette, CO).

\section{Generation of adenoviral vectors}

Adenoviral vector for expressing DJ-1-GFP fusion protein was prepared as described using pAdEASY system [31].

\section{Protein extraction and immunoblotting}

Cells transfected with pEGFP-DJ-1 or pEGFP vectors (treated or untreated) were lysed. The proteins were eluted by boiling in 3X SDS sample buffer and resolved by SDS-PAGE. Protein concentration was determined using amido black method [32]. The proteins were transferred to nitrocellulose membrane for immunoblot analysis as previously described [9]. Primary antibodies for DJ-1 (1:1000), PARP (1:3000), GFP (1: 1000), caspase 9 (1:1000), pAKT (1:1000), AKT (1:1000), PTEN (1:250) or actin (1:750) were used. The secondary antibody used was conjugated to horseradish peroxidase (HRP) (1:10 000). The blots were developed using the ECL kit (Millipore, Billerica, MA). Exposed films were scanned and bands of interest were quantified using Gene-Tools version 3.06.04 from SynGene (Cambridge, U.K.).

\section{Cell Adhesion Assay}

The cell adhesion assay was done as described [33]. Briefly, cells were either infected with DJ-1-GFP adenovirus and control GFP adenovirus for $24 \mathrm{~h}$. Cell suspension $\left(1 \times 10^{4}\right.$ cells $)$ was added to the wells of a 96-well microtitre plate coated with collagen type IV, fibronectin, laminin or poly-L-lysine and incubated for $20 \mathrm{~min}$. At the end of incubation, MTT assay was performed. Cells treated with poly-L-lysine served as positive control. Data is expressed as the mean $\pm \mathrm{SE}$ of three independent experiments. 


\section{Cell Proliferation Assay}

Cells were either infected with DJ-1-GFP adenovirus or control GFP adenovirus for $24 \mathrm{~h}$, or transfected with DJ-1 siRNA or control siRNA for $48 \mathrm{~h}$. $100 \mu \mathrm{l}$ of cell suspension $\left(1 \times 10^{3}\right.$ cells $)$ was plated in a 96-well microtitre plate in triplicates. At the end of 0 , 24, 48, and 96 h, MTT assay was performed. Data is expressed as the mean $\pm \mathrm{SE}$ of three independent experiments.

\section{Wound Healing Assay}

The wound assay was done as described [34]. Briefly, cells were either infected with DJ-1-GFP adenovirus or control GFP adenovirus for $24 \mathrm{~h}$, or transfected with DJ-1 siRNA or control siRNA for $48 \mathrm{~h}$. At the end of incubation a wound was created manually. The wound was then visualized under an automated time-lapse microscope equipped with a temperature control chamber. The images of the same region were acquired automatically for 24-36 h.

\section{Matrigel Invasion Assay}

In vitro invasion assay was performed using Matrigel-coated 24well chambers according to the manufacturer's instructions (BD Bioscience, Bedford, MA) and as described [25]. Briefly, the cells were either infected with DJ-1-GFP adenovirus or control GFP adenovirus for $24 \mathrm{~h}$, or transfected with DJ-1 siRNA or control siRNA for $48 \mathrm{~h}$. After rehydration of the chambers, the cells $\left(5 \times 10^{4}\right.$ cells per chamber $)$ in $500 \mu$ l growth medium were seeded onto the upper chamber. In the lower chamber, $500 \mu \mathrm{l}$ DMEM plus $10 \%$ FCS was placed. Invasion of cells was measured as number of cells invaded from a defined area of the Matrigelcoated microfilter through micropores in $24 \mathrm{~h}$. The micropore filters were stained with haematoxylin and eosin and cells that migrated through the filters were counted in eight representative areas under an inverted microscope (Axioplan 2) at $400 \times$ magnification and expressed as the mean $\pm \mathrm{SE}$ of three independent experiments.

\section{Confocal microscopy}

Cells grown on coverslips were transfected with myc-DJ-1 and GFP-PTEN plasmids. Cells were fixed and stained with antibody against myc. For endogenous staining, HES and 12-Z cells were fixed and stained with antibodies against DJ-1 and PTEN. Cells were then stained with flurophores conjugated secondary antibodies and mounted in Vectashield mounting media containing DAPI (Burlingame, CA). The cells were analyzed for colocalization using a LSM 510 Meta confocal microscope (Carl Zeiss Microimaging, Jena). Serial optical sections in the $\mathrm{Z}$-axis of the cells were collected at $0.33 \mu \mathrm{m}$ intervals with a $63 \times$ oil immersion objective lens (NA 1.4). Quantitative analysis of colocalization was carried out by using LSM 510 software.

\section{Co-immunoprecipitation}

HES cells transfected with the myc-DJ-1 and GFP-PTEN plasmids for $48 \mathrm{~h}$, were lysed at $4{ }^{\circ} \mathrm{C}$ for 20 minutes in a buffer containing $25 \mathrm{mM}$ Tris-HCl, $\mathrm{pH} 7.4,150 \mathrm{mM} \mathrm{NaCl}, 1.0 \%$ Triton X-100, $1 \mathrm{mM}$ PMSF, 0.1\% BSA, $5 \mathrm{mM} \mathrm{EDTA} \mathrm{and}$ protease inhibitor cocktail (Roche). Lysates were centrifuged at $10,000 \mathrm{~g}$ for 10 minutes at $4^{\circ} \mathrm{C}$ and the supernatant was used for immunoprecipitation using $2 \mu \mathrm{g}$ of c-myc rabbit polyclonal antibody or $2 \mu \mathrm{g}$ of normal rabbit IgG as control antibody. Complexes were precipitated using A/G plus agarose beads (Santa Cruz), washed and lysed in $20 \mu \mathrm{l}$ of $3 \mathrm{X}$ SDS sample buffer. The samples were resolved on 10\% SDS-PAGE and subjected to immunoblot analysis as described above.

\section{Statistical analysis}

Significant differences in the data were determined by one-way and two-way analysis of variance (ANOVA) and Student's t-test (PRISM, version 3). Post hoc comparisons were made using Bonferroni test. $\mathrm{P}$ values of $<0.05$ were considered significant.

\section{Supporting Information}

Figure S1 Expression of DJ-1 on various extracellular matrix components. Immunoblot analysis showing the expression levels of $\mathrm{DJ}-1$ on various extracellular matrix components after infection with DJ-1-GFP adenovirus using GFP antibody. Cells which were plated on uncoated wells served as control.

(TIF)

Figure S2 Effect of DJ-1 and control siRNA on DJ-1 expression and endometriotic cell proliferation. Effect of DJ-1 siRNA on expression of DJ-1 protein after 48, 72, 96, 120, and $144 \mathrm{~h}$ post transfection (A). Effect of ctrl siRNA on expression of $\mathrm{DJ}-1$ protein after $48,72,96,120$, and $144 \mathrm{~h}$ post transfection (B). Cells which were not transfected with either DJ-1 siRNA or control siRNA served as control. Endometriotic epithelial (12-Z) (C) and stromal (22-B) (D) cells were transfected with either DJ-1 siRNA or ctrl siRNA and plated on 96 well plates. Cell proliferation was determined by MTT assay. Results are expressed as the percentage of control at time $0 \mathrm{~h}$. *Asterisk indicates significant differences $(\mathrm{P}<0.05)$ between $\mathrm{DJ}-1$ knockdown cells and controls, as determined by one way ANOVA with post hoc Bonferroni test. Cells which were not transfected with either DJ-1 siRNA or control siRNA served as control. Numerical data are expressed as mean $\pm \mathrm{SE}$ of three independent experiments. (TIF)

Figure S3 Expression of DJ-1 after infection with DJ-1GFP and control adenovirus. Immunoblot analysis showing the expression levels of DJ-1 on infection with either DJ-1-GFP adenovirus (A) or GFP control adenovirus (C) using GFP antibody after 24, 48, 72, 96, and $120 \mathrm{~h}$ after infection. Cells which were transfected with either DJ-1-GFP or GFP control plasmid served as control. B and D represent densitometry analysis of DJ-1-GFP and GFP protein to actin ratio based on immunoblot analysis, respectively.

(TIF)

Figure S4 Wound healing assay to determine migration in normal and endometriotic cells. Panels in A show the temporal sequence $(0,12$ and $24 \mathrm{~h}$ ) of wound healing in normal endometrial epithelial (HES) and endometriotic epithelial (12-Z) cells. Panels in B show the temporal sequence (0, 12 and $24 \mathrm{~h}$ ) of wound healing in normal endometrial stromal (Sht 290) and endometriotic stromal (22-B) cells. Photographs were taken by time lapse microscopy at initial time $(0 \mathrm{~h})$ till the termination of the experiments. Experiments were repeated in triplicates. (TIF)

Figure S5 Role of DJ-1 in normal endometrial and endometriotic stromal cell migration. Inhibition of DJ-1 in endometriotic stromal cells (22-B) does not significantly affect migration (A). Overexpression of $\mathrm{DJ}-1$ in normal endometrial stromal cells (Sht 290) does not significantly affect migration (B). Cells were either transfected with DJ-1 siRNA, or with control siRNA and $48 \mathrm{~h}$ post transfection wound assay was performed. For overexpression, cells were either infected with DJ-1-GFP adenovirus, or with control adenovirus and $24 \mathrm{~h}$ post infection wound assay was performed. Wound photographs were taken by time 
lapse microscopy at initial time $(0 \mathrm{~h})$ till the termination of the experiments. The experiments were repeated in triplicates. (TIF)

Figure S6 Co-localization of DJ-1 with PTEN in Ishikawa and HeLa cells. Ishikawa cells transfected with GFPPTEN and myc- DJ-1 were fixed and stained with anti-myc antibody (red). HeLa cells were stained with antibodies against PTEN (green) and DJ-1 (red). The images were visualized with a confocal microscopy.

(TIF)

\section{References}

1. Giudice LC, Kao LC (2004) Endometriosis. Lancet 364: 1789-1799.

2. Varma R, Rollason T, Gupta JK, Maher ER (2004) Endometriosis and the neoplastic process. Reproduction 127: 293-304.

3. Vinatier D, Cosson M, Dufour $\mathrm{P}$ (2000) Is endometriosis an endometrial disease. Eur J Obstet Gynecol Reprod Biol 91: 113-125.

4. Matsuzaki S, Canis M, Vaurs-Barriere C, Boespflug-Tanguy O, Dastugue B, et al. (2005) DNA microarray analysis of gene expression in eutopic endometrium from patients with deep endometriosis using laser capture microdissection. Fertil Steril 84: 1180-1190.

5. Wu Y, Kajdacsy-Balla A, Strawn E, Basir Z, Halverson G, et al. (2006) Transcriptional characterizations of differences between eutopic and ectopic endometrium. Endocrinology 147: 232-246.

6. Burney RO, Talbi S, Hamilton AE, Vo KC, Nyegaard M, et al. (2007) Gene expression analysis of endometrium reveals progesterone resistance and candidate susceptibility genes in women with endometriosis. Endocrinology 148: 3814-3826.

7. Fowler PA, Tattum J, Bhattacharya S, Klonisch T, Hombach-Klonisch S, et al. (2007) An investigation of the effects of endometriosis on the proteome of human eutopic endometrium: A heterogeneous tissue with a complex disease. Proteomics 7: 130-142.

8. Stephens AN, Hannan NJ, Rainczuk A, Meehan KL, Chen J, et al. (2010) Posttranslational modifications and protein-specific isoforms in endometriosis revealed by 2D DIGE. J Proteome Res 9: 2438-2449.

9. Rai P, Kota V, Deendayal M, Shivaji S (2010) Differential proteome profiling of eutopic endometrium from women with endometriosis to understand etiology of endometriosis. J Proteome Res 9: 4407-4419.

10. Taira T, Takahashi K, Kitagawa R, Iguchi-Ariga SM, Ariga H (2001) Molecular cloning of human and mouse DJ-1 genes and identification of Sp1dependent activation of the human DJ-1 promoter. Gene 263: 285-292.

11. Nagakubo D, Taira T, Kitaura H, Ikeda M, Tamai K, et al. (1997) DJ-1, a novel oncogene which transforms mouse NIH3T3 cells in cooperation with ras. Biochem Biophys Res Commun 231: 509-513.

12. MacKeigan JP, Clements CM, Lich JD, Pope RM, Hod Y, et al. (2003) Proteomic profiling drug-induced apoptosis in non-small cell lung carcinoma: identification of RS/DJ-1 and RhoGDIalpha. Cancer Res 63: 6928-6934.

13. Davidson B, Hadar R, Schlossberg A, Sternlicht T, Slipicevic A, et al. (2008) Expression and clinical role of DJ-1, a negative regulator of PTEN, in ovarian carcinoma. Hum Pathol 39: 87-95.

14. Le Naour F, Misek DE, Krause MC, Deneux L, Giordano TJ, et al. (2001) Proteomics-based identification of RS/DJ-1 as a novel circulating tumor antigen in breast cancer. Clin Cancer Res 7: 3328-3335.

15. Liu H, Wang M, Li M, Wang D, Rao Q et al. (2008) Expression and role of DJ1 in leukemia. Biochem Biophys Res Commun 375: 477-483.

16. Kim RH, Peters M, Jang Y, Shi W, Pintilie M, et al. (2005) DJ-1, a novel regulator of the tumor suppressor PTEN. Cancer Cell 7: 263-273.

17. Shinbo Y, Taira T, Niki T, Iguchi-Ariga SM, Ariga H (2005) DJ-1 restores p53 transcription activity inhibited by Topors/p53BP3. Int J Oncol 26: 641-648.

\section{Acknowledgments}

We thank Dr. Valina L. Dawson, Institute for Cell Engineering, Johns Hopkins University School of Medicine, Baltimore, Maryland, USA for pcDNA3.1-Myc-His-wild type DJ-1 and Dr. Kenneth M. Yamada, Craniofacial Developmental Biology and Regeneration Branch, National Institute of Dental Research, National Institutes of Health, Bethesda, Maryland, USA for pGFP-PTEN plasmid.

\section{Author Contributions}

Conceived and designed the experiments: PR SS. Performed the experiments: PR. Analyzed the data: PR SS. Wrote the paper: PR SS.

18. Fan J, Ren H, Jia N, Fei E, Zhou T, et al. (2008) DJ-1 decreases Bax expression through repressing p53 transcriptional activity. J Biol Chem 283: 4022-4030.

19. Yokota T, Sugawara K, Ito K, Takahashi R, Ariga H, et al. (2003) Down regulation of DJ-1 enhances cell death by oxidative stress, ER stress, and proteasome inhibition. Biochem Biophys Res Commun 312: 1342-1348.

20. Taira T, Saito Y, Niki T, Iguchi-Ariga SM, Takahashi K, et al. (2004) DJ-1 has a role in antioxidative stress to prevent cell death. EMBO Rep 5: 213-218.

21. Kalluri R (2003) Basement membranes: structure, assembly and role in tumor angiogenesis. Nat Rev Cancer 3: 422-433.

22. Zhou W, Freed CR (2005) DJ-1 up-regulates glutathione synthesis during oxidative stress and inhibits A53T alpha-synuclein toxicity. J Biol Chem 280: $43150-43158$.

23. Shen Z, Jiang Z, Ye D, Xiao B, Zhang X, et al. (2010) Growth inhibitory effects of DJ-1-small interfering RNA on laryngeal carcinoma Hep-2 cells. Med Oncol;DOI: $10.1007 / \mathrm{s} 12032-010-9474-7$.

24. Lucidi RS, Witz CA, Chrisco M, Binkley PA, Shain SA, et al. (2005) A novel in vitro model of the early endometriotic lesion demonstrates that attachment of endometrial cells to mesothelial cells is dependent on the source of endometrial cells. Fertil Steril 84: 16-21.

25. Banu SK, Lee J, Speights VO, Jr., Starzinski-Powitz A, Arosh JA (2008) Cyclooxygenase-2 regulates survival, migration, and invasion of human endometriotic cells through multiple mechanisms. Endocrinology 149: 1180-1189.

26. Kim YC, Kitaura H, Taira T, Iguchi-Ariga SM, Ariga H (2009) Oxidation of DJ-1-dependent cell transformation through direct binding of DJ-1 to PTEN. Int J Oncol 35: 1331-1341.

27. Davidson L, Maccario H, Perera NM, Yang X, Spinelli L, et al. (2010) Suppression of cellular proliferation and invasion by the concerted lipid and protein phosphatase activities of PTEN. Oncogene 29: 687-697.

28. Zeitvogel A, Baumann R, Starzinski-Powitz A (2001) Identification of an invasive, Ncadherin- expressing epithelial cell type in endometriosis using a new cell culture model. Am J Pathol 159: 1839-1852.

29. Desai NN, Kennard EA, Kniss DA, Friedman CI (1994) Novel human endometrial cell line promotes blastocyst development. Fertil Steril 61: 760-766.

30. Barbier CS, Becker KA, Troester MA, Kaufman DG (2005) Expression of exogenous human telomerase in cultures of endometrial stromal cells does not alter their hormone responsiveness. Biol Reprod 73: 106-114.

31. He TC, Zhou S, da Costa LT, Yu J, Kinzler KW, et al. (1998) A simplified system for generating recombinant adenoviruses. Proc Natl Acad Sci USA 95: 2509-2514.

32. Henkel AW, Bieger SC (1994) Quantification of proteins dissolved in an electrophoresis sample buffer. Anal Biochem 223: 329-331.

33. Humphries MJ (2001) Cell adhesion assays. Mol Biotechnol 1: 57-61.

34. Liang CC, Park AY, Guan JL (2007) In vitro scratch assay: a convenient and inexpensive method for analysis of cell migration in vitro. Nat Protoc 2: 329-333. 